\title{
Properties of Cassava Starch based Bioplastic Reinforced by Nanoclay
}

\author{
Nanang Eko Wahyuningtiyas ${ }^{1,2^{*}}$ and Heru Suryanto ${ }^{2}$ \\ ${ }^{1}$ Environmentalist, Samarinda, Kalimantan Timur, Indonesia \\ ${ }^{2}$ Department of Mechanical Engineering, Faculty of Engineering, Universitas Negeri Malang \\ *nanang.ftum@gmail.com
}

\section{ABSTRACT}

Synthetic Synthetic plastic is chemical materials which cause severe environmental problems. Incinerating plastic waste leads to release of hazardous gases, which is not good for humans. Bioplastic can help reduce the dependence on fossil fuels and petroleum, that bioplastic can solve the problem of synthetic plastic use. This research aims to define the properties of the cassava starch-based bioplastic reinforced by nanoclay. Methods were experimental with bioplastic component of cassava starch, glycerol as plasticizer and nanoclay as reinforcement. The bioplastic was analyzed using XRD, tensile test, moisture absorption, biodegradability, and compared with another bioplastic. The results show that the addition of nanoclay into bioplastic results increasing the tensile strength of bioplastic also increases from 5.2 MPa to 6.3 MPa. This research revealed that complete degradation of nanoclay reinforced bioplastic could be achieved on the 6th day.

Copyright (C) 2018Journal of Mechanical Engineering Science and Technology

All rights reserved

Keywords: biodegradability, nanoclay, starch-based bioplastic, tensile strength

\section{Introduction}

Bioplastic Bioplastic is very important to use because able to maintain a sustainable environment and to prevent the disposal synthetic plastic wastes [1] that damaging the ecology includes the lands, waterways, and air pollution from plastic combustion. Synthetic plastic takes 50 years to decompose in nature, whereas bioplastic requires 10 to 20 times faster to decompose in nature [2]. In 2014, the production of bioplastic around the world was 1.7 million tons [3] and will increase to reach 6.2 million tons by 2018 [4].

In Indonesia, synthetic plastic consumption reaches 5.2 million tons in 2016, but bioplastic consumption is lower than 52,000 tons or $1 \%$ of synthetic plastic consumption [5]. Bioplastic is a potential environmentally friendly material to reduce the usage of petroleum-based plastic. Starchbased bioplastics were the most utilized bioplastic, due to their low $\mathrm{CO}_{2}$ emission [4] and able to decompose by microorganisms as well as cellulose and lignin [6].

Thermoplastic starch is a polymer made of starch or natural polymer renewable [7], through the process thermomechanical treatment in the mixed of suitable plasticizers, such as glycerol [8]. Starch is a renewable source of packaging technology [9], due to its abundance, low cost, and ecofriendliness [10] [11] [12]. Cassava contains a large amount of starch, which is capable of bioplastic production [2]. Bioplastic from cassava starch lower price as compared to other starches, so it becomes a great potential for bioplastic. Indonesia as the third-largest producer of cassava in the world [13] has the great potency to realize the bioplastic as a material substitution to synthetic plastic through exploring more deeply about cassava starch-based bioplastic.

Besides the advantages, the cassava starch-based bioplastic has some limitations such as high production cost [14], high water affinity [15], and poor mechanical properties [14], due to of the intramolecular and intermolecular bonds in the starch [7]. Some of the techniques conducted to improve the mechanical properties and to reduce high water affinity especially in bio-based packaging application through adding organic fillers (nanocomposites), such as using nanofibers, nanotube, nanowhisker and nanoclay [16]. 
Nanoclay in the forms of clay is abundant in nature, versatility, and respectability toward the environment [17]. Nanoclay can reinforce bioplastic in order to enhance mechanical properties, enhance their mechanical water resistance, decrease of water vapor permeability and flame retardance [15] [16] [17] when silicate component of nanoclay layers are well dispersed in the bioplastic [18]. Hence, the aim of the research was to investigate the properties of cassava starchbased bioplastic reinforced by nanoclay.

\section{Material and method}

\section{A. Material}

The cassava starch obtained from a local source, Malang, East Java, Indonesia was used as bioplastic material. Glycerol with a concentration of $98 \%$ was used as a plasticizer supplied by CV. Makmur Sejati, Malang, East Java, Indonesia. Surface modified nanoclay containing 25-30\% (w/t) trimethyl stearyl ammonium was provided by the Sigma Aldrich.

\section{B. Bioplastic Synthesis}

Glycerol with concentration $1.5 \%$ (v/v) was dissolved into the distilled water of $98.5 \mathrm{ml}$ while stirred on a magnetic stirrer at $900 \mathrm{rpm}$ for $5 \mathrm{~min}$. The solution was added nanoclay by concentrations of $5.0 \%(\mathrm{~b} / \mathrm{b})$ and heated on a hot magnetic stirrer for $\pm 45 \mathrm{~min}$ at $\pm 80^{\circ} \mathrm{C}$. The homogenizing process was conducted using ultrasonic wave $20 \mathrm{kHz}$ for $30 \mathrm{~min}$. After sonication process, Solution was added with cassava starch by the concentration of $5.0 \%(\mathrm{~b} / \mathrm{v})$ then heated on a magnetic stirrer at $\pm 80^{\circ} \mathrm{C}$ while being stirred at $900 \mathrm{rpm}$ for $45 \mathrm{~min}$. Bioplastic solution was poured into the mold then dried in an oven at $50^{\circ} \mathrm{C}$ for $24 \mathrm{~h}$, and finally kept in a desiccator [2].

\section{XRD Analysis}

XRD analysis was conducted using PanAnalitical type X-Pert Pro Diffractometer system at room temperature. The diffracted intensity of $\mathrm{CuK} \alpha$ radiation with wavelength $(\lambda)$ of $1.54 \AA$ was recorded between $2^{\circ}$ and $60^{\circ}$ with a scanning rate of $0.02^{\circ}$ per step at $30 \mathrm{~mA}$ and $40 \mathrm{kV}$.

\section{Mechanical properties}

The tensile strength of nanoclay reinforced bioplastic was determined using a tensile tester with a load capacity of $50 \mathrm{~N}$. Bioplastic was cut with size $50 \times 5 \mathrm{~mm}^{2}$ then prepared at a mounting card as shown in Figure 1. Specimens were clamped at both the ends then pulled with a constant speed of $0.025 \mathrm{~ms}^{-1}[19]$..

\section{E. Water Absorption}

The water absorption measurements were carried out at a relative humidity of $80 \%$ at room temperature using ASTM D570-98. The water absorption test identified the ability of bioplastic to absorb the water [20]. Dried nanoclay reinforced bioplastic cut into $10 \times 10 \mathrm{~mm}^{2}$ and weighed for initial weigh. The moisture absorption data of nanoclay reinforced bioplastic was obtained by placing the sample in a bath of distilled water for $24 \mathrm{~h}$ at ambient temperature. After that, the sample was removed and wiped off and immediately weighed again as final weigh. The water absorption capacity of nanoclay reinforced bioplastic can be calculated using equation 3 based on 5 replications.

$$
\text { Water absorption }=\frac{\text { Final Weight }- \text { Initial Weight }}{\text { Initial Weight }} \times 100 \%
$$
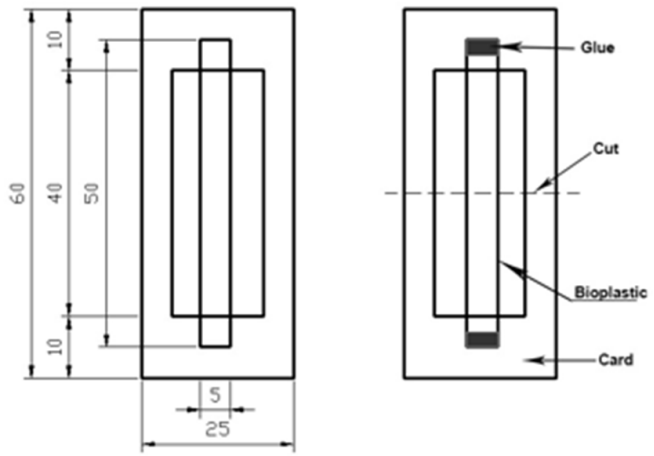
Fig. 1.Tensile test specimens using the mounting card for bioplastic sheet

\section{F. Biodegradability}

The The biodegradable behavior of nanoclay reinforced bioplastic was determined using soil burial decomposition test [21]. Nanoclay reinforced bioplastic were cut into $10 \times 10 \mathrm{~mm}^{2}$, then, buried in the ground at 80-mm depth; the burial duration varied from 1 to 7 days. Prior to burial, the initial weight was determined and the final weight (weight after decomposition) of the bioplastic was measured. The decomposition of each sample was determined by equation 4 for weight loss [2]:

$$
\text { Biodegradability }=\frac{\text { Final Weight }- \text { Initial Weight }}{\text { Initial Weight }} \times 100 \%
$$

\section{Results and discussion}

\section{A. XRD Analysis}

Figure 2 shows diffractogram of cassava starch bioplastic and nanoclay reinforced cassava starch bioplastic. Peak diffraction of cassava starch bioplastic was about $2 \theta$ of $16.89^{\circ}$ and $19.63^{\circ}$. Cassava starch is a semi-crystalline material consisting of crystal units and amorphous units [22]. After reinforced by nanoclay of $5.0 \%(\mathrm{~b} / \mathrm{b})$, peak diffraction of the shift were about $2 \theta$ of $16.65^{\circ}$ and $19.69^{\circ}$ was due to the intercalated and exfoliated process. The intensity of peak located at $19.69^{\circ}$ was an increase because of additional intensity from nanoclay having high peak located at $19.8^{\circ}$ [23]. The thermoplastic cassava enters the clay galleries and forces apart the platelets resulting the increase of d-spacing [24]. The increase in the d-spacing exhibit the change in the formation of a composite structure with the intercalated of thermoplastic chains in the nanoclay layers gallery. As more polymers insert into the clay galleries and push the layers even further. When a complete exfoliated structure of nanocomposite is reached, the XRD peak becomes wider [25] [26].

The phenomenon of exfoliated is desirable for the improvement of mechanical properties [27]. The addition of nanoclay can increase crystallinity because the nanoclay play as a nucleating agent and accelerates the crystallization process resulting in a higher crystallinity [28].

\section{B. Mechanical Properties}

Figure 3 shows the curve of tensile properties that indicate increasing the tensile strength of bioplastic due to the addition of nanoclay. Nanoclay makes the interface transfers the load or stress from bioplastic to nanoclay through intercalation mechanism.

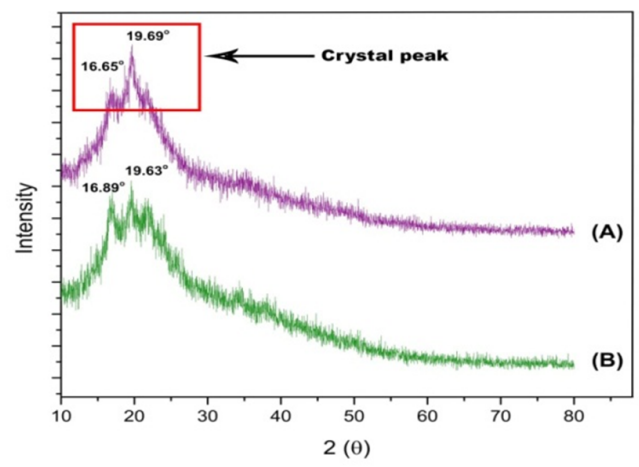

Fig. 2.Diffractogram of (A) nanoclay reinforced cassava bioplastic 5.0\% (b/b) (B) bioplastic cassava starch

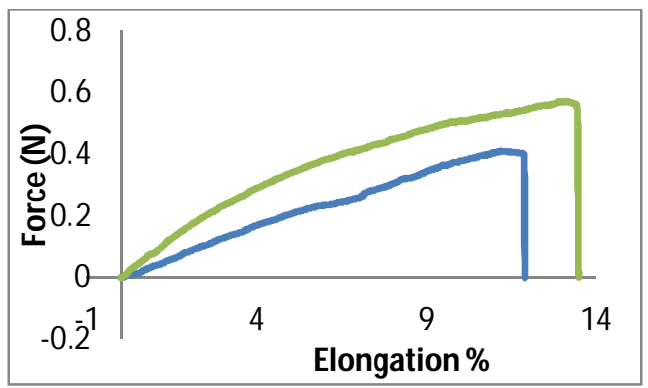


Fig. 3. Tensile test curve: A. Cassava starch-based bioplastic, B. nanoclay reinforced bioplastic $5.0 \%$ (b/b)

Table 1. Mechanical properties of cassava starch based bioplastic and Nanoclay reinforced bioplastic

\begin{tabular}{cccc}
\hline Sample & Tensile strength (MPa) & Elongation (\%) & Young's modulus (MPa) \\
\hline $\begin{array}{c}\text { Cassava starch based } \\
\text { bioplastic }\end{array}$ & 5.2 & 11.9 & 71.64 \\
\hline $\begin{array}{c}\text { Nanoclay reinforced } \\
\text { bioplastic 5.0\% }(\mathrm{b} / \mathrm{b})\end{array}$ & 6.3 & 13.5 & 47 \\
\hline
\end{tabular}

Increasing nanoclay addition in bioplastic cause lower tensile strength due to a large number of nanoclay particles tend to agglomerate into larger particles, which affect the intercalation effect of nanoclay particles in the polymer (bioplastic) [29]. Young's modulus bioplastic from cassava starch and nanoclay reinforced bioplastic $5.0 \%(\mathrm{~b} / \mathrm{b})$ was decreased in Table 1 , due to glycerol as plasticizers increase nanoclay reinforced bioplastic $5.0 \%(\mathrm{~b} / \mathrm{b})$ flexibility that has the ability to reduce internal hydrogen bonding between polymer chains, resulted in bioplastic with lower Young's modulus and high flexibility [30].

Increased bioplastic tensile strength, due to increasing XRD peak intensity that correlating with enhancing the crystallinity of cassava starch based bioplastic. The crystallinity of polymer affects various chemical properties and physical technologies and there is also a correlation between crystallinity and mechanical strength of polymer [31]

\section{Moisture Absorption}

Addition of Nanoclay $5.0 \%$ (b/b) into bioplastic enhances the water absorption shown in Figure 4. The crystalline regions offer less free volume than amorphous regions in the nanoclay reinforced bioplastic so that air and gas vapor will be more difficult to enter [32] and due to also its hygroscopic nature of nanoclay [33] which easily absorbs $\mathrm{H}_{2} \mathrm{O}$ [18]. Absorption of $\mathrm{H}_{2} \mathrm{O}$ causes the galleries to expand and the nanoclay to swell [34], that nanoclay reinforced bioplastic is more hydrophilic.

\section{Biodegradability}

The addition of nanoclay has enormous potential to either increase rate of decomposition until 6 days in Figure 5. Nanoclay reinforced bioplastic 5.0\% (b/b) increase the amount of decomposition, that could be, due to aluminum Lewis acid site from nanoclay that can catalyze during the process of hydrolysis. Also, the presence of nanoclay increased the substrate polarity and water absorption which enhanced the heterogenic rate of hydrolysis decomposition [18] [34] [35]. Moreover, cassava starch-based bioplastic increase the hydrophilicity through eliminating the regular crystalline structure from nanoclay reinforced bioplastic, facilitated the attack of microorganism into the bulk of nanoclay reinforced bioplastic [36], that cause hydroxyl groups in the silicate layers initiated heterogeneous hydrolysis after absorbing water from the compost, that creates nanoclay reinforced bioplastic 5.0\% (b/b) decomposition into very small fragments and eventually disappeared with the compost [18]. Decomposition in soil based on the diffusion of living microorganisms in aqueous soils [36]. The effect of nanoclay can speed up the decomposition process.

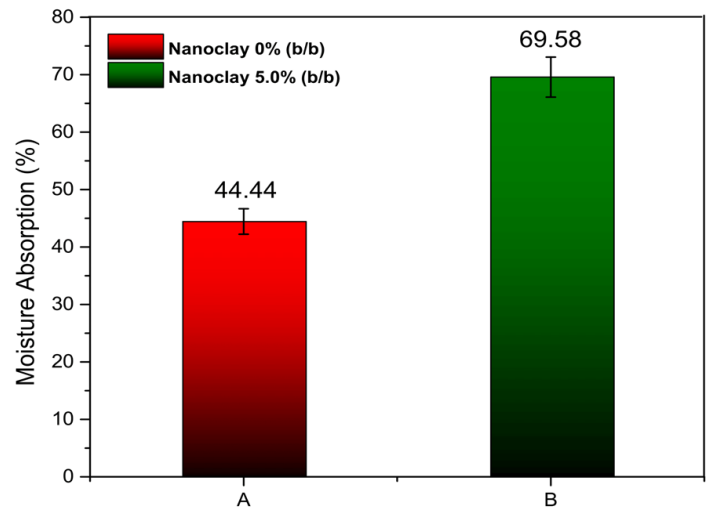


Fig. 4. The rate of moisture absorption of nanoclay reinforced bioplastic

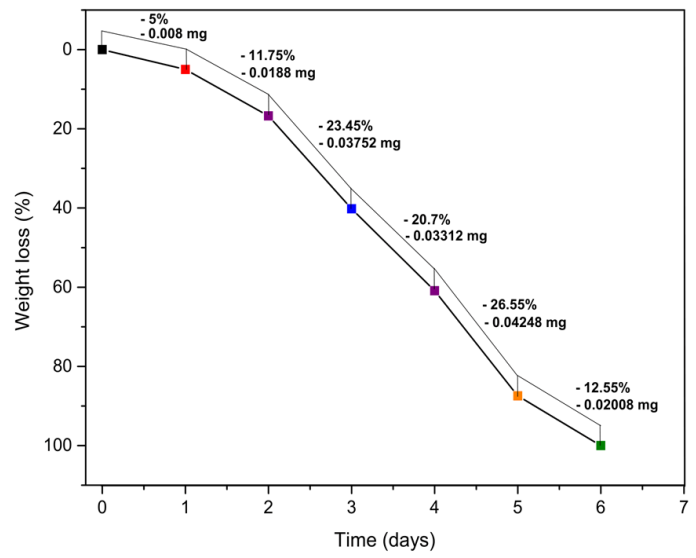

Fig. 5. Results of nanoclay reinforced bioplastic decomposition testing

Table 2. Decomposition duration of some plastic-types

\begin{tabular}{ccc}
\hline Sample & Decomposition times & References \\
\hline Bioplastic cassava starch filler nanoclay $5.0 \%(\mathrm{~b} / \mathrm{b})$ & 6 days & This study \\
\hline Bioplastic cassava starch & 12 days & {$[2]$} \\
\hline Bioplastic cassava starch filler chitosan & 8 days & {$[37]$} \\
\hline Bioplastic potato starch & 5 days & {$[38]$} \\
\hline Bioplastic corn starch & 7 days & {$[39]$} \\
\hline Bioplastic Gluten & 50 days & {$[10]$} \\
\hline Synthetic plastic & $>50$ years & {$[40]$} \\
\hline
\end{tabular}

Decomposition of bioplastic from cassava starch reinforced with nanoclay $5.0 \%$ (b/b) (6 days) slower from bioplastic from potato starch (5 days), but faster from bioplastic from cassava starch filler chitosan (8 days), bioplastic from corn starch (7 days), bioplastic from cassava starch (12 days), bioplastic from gluten (50 days), and synthetic plastic as shown in Table 2.

\section{Conclusion}

This research has demonstrated the potential to use bioplastic from cassava starch reinforced with nanoclay from renewable resources. Nanoclay in cassava starch bioplastic enhanced the peak structure of bioplastic which this structure able to increase the tensile strength and reduce water absorption of bioplastic.

\section{Acknowledgments}

We are grateful to the Ministry of Research, Technology, and Higher Education, Indonesia, and the Universitas Negeri Malang that supporting this study through PDUPT program with contract No. 1.3.32/UN.14/LT/2018.

\section{References}

[1] N. E. Wahyuningtiyas, H. Suryanto, E. Rudiyanto, Sukarni, and P. Puspitasari, "Thermogravimetric and kinetic analysis of cassava starch based bioplastic," JMEST, vol. 1, no. 2, pp. 1-16, 2017.

[2] N. E. Wahyuningtiyas and H. Suryanto, "Analysis of Biodegradation of Bioplastics Made of Cassava Starch," JMEST, vol. 1, no. 1, pp. 41-54, 2017.

[3] S. M. Emadian, T. T. Onay, and B. Demirel, "Biodegradation of bioplastics in natural environments," Waste Manag., vol. 59, pp. 526-536, 2017. 
[4] N. A. Mostafa, Farag Awatef A., H. M. Abo-dief, and A. M. Tayeb, "Production of biodegradable plastic from agricultural wastes," Arab. J. Chem., pp. 4-11, 2014.

[5] Tempo, "Produk Industri Bioplastik Ditargetkan Tumbuh 5\%," 2017. [Online]. Available: https://bisnis.tempo.co/read/873501/produk-industri-bioplastik-ditargetkan-tumbuh-5-persen. [Accessed: 25-Mar-2018].

[6] L. Averous, "Biodegradable Multiphase Systems Based on Plasticized Starch: A Review," Macromol. Sci. Part C Polym. Rev., vol. 44, no. 3, pp. 231-274, 2004.

[7] N. Wang, Y. Jiugao, M. Xiafei, and H. Chunmei, "An Investigation of the Physical Properties of Extruded Glycerol- and Formamide-Plasticized Cornstarch," Thermoplast. Compos. Mater., vol. 22, no. 3, pp. 273-291, 2009.

[8] N. F. Magalhães and C. T. Andrade, "Thermoplastic cornstarch/clay hybrids: Effect of clay type and content on physical properties," Carbohydr. Polym., vol. 75, no. 4, pp. 712-718, Feb. 2009.

[9] F. Razza, F. Degli Innocenti, A. Dobon, C. Aliaga, C. Sanchez, and M. Hortal, "Environmental profile of a bio-based and biodegradable foamed packaging prototype in comparison with the current benchmark," J. Clean. Prod., vol. 102, pp. 493-500, Sep. 2015.

[10] S. Domenek, P. Feuilloley, J. Gratraud, M.-H. Morel, and S. Guilbert, "Biodegradability of wheat gluten based bioplastics," Chemosphere, vol. 54, no. 4, pp. 551-559, Jan. 2004.

[11]Y. Song and Q. Zheng, "Preparation and properties of thermo-molded bioplastics of glutenin-rich fraction," Cereal Sci., vol. 48, no. 1, pp. 77-82, 2008.

[12]G. J. Gutierrez, P. Partal, M. G. M., and C. Gallegos, "Effect of processing on the viscoelastic, tensile and optical properties of albumen/starch-based bioplastics," Carbohydr. Polym., vol. 84, no. 1, pp. 308$315,2011$.

[13]E. U. Aprilia, "Tiga Negara Asia Berpotensi Jadi Tujuan Ekspor Singkong," Tempo, 2011. [Online]. Available: https://bisnis.tempo.co/read/339185/tiga-negara-asia-berpotensi-jadi-tujuan-ekspor-singkong. [Accessed: 25-Mar-2018].

[14]R. Jain and A. Tiwari, "Biosynthesis of planet friendly bioplastics using renewable carbon source," $J$. Environ. Heal. Sci. Eng., vol. 13, no. 1, p. 11, Dec. 2015.

[15] O. V. López, L. A. Castillo, M. A. García, M. A. Villar, and S. E. Barbosa, "Food packaging bags based on thermoplastic corn starch reinforced with talc nanoparticles," Food Hydrocoll., vol. 43, pp. 18-24, Jan. 2015.

[16] V. G. L. Souza and F. A. Luisa, "Nanoparticles in food packaging: Biodegradability and potential migration to food-A review," Food Packag. Shelf Life, vol. 8, pp. 63-70, 2016.

[17]O. T. Carvalho, L. Averous, and C. C. Tadini, "Mechanical properties of cassava starch-based nanobiocomposites," Int. Congr. Eng. Food, Athens, Greece, pp. 111-112, 2011.

[18]L. S. Kyong, Seong Dong Gi, and Youn Jae Ryoun, "Degradation and rheological properties of biodegradable nanocomposites prepared by melt intercalation method," Fibers Polym., vol. 6, no. 4, pp. 289-296, 2005.

[19]ASTM D 882, Standard Test Method for Tensile Properties of Thin Plastic Sheeting. United States: ASTM International, 2004.

[20] ASTM D 570, Standard Test Method for Water Absorption of Plastics. 2004.

[21]C. R. Di Franco, V. P. Cyras, J. P. Busalmen, R. A. Ruseckaite, and A. Vázquez, "Degradation of polycaprolactone/starch blends and composites with sisal fibre," Polym. Degrad. Stab., vol. 86, no. 1, pp. 95-103, 2004.

[22]Q. P. Zhong and Xia Wen Shui, "Physicochemical properties of edible and preservative films from chitosan/cassava starch/gelatin blend plasticized with glycerol," Food Technol. Biotechnol., vol. 46, no. 3, pp. 262-269, 2008.

[23]H. Suryanto, P. T. Hutomo, R. Wanjaya, and P. Puspitasari, "The Structure of Bioplastic from Cassava Starch with Nanoclay Reinforcement," in AIP International Proceeding International Mechanical Engineering and Engineering Education (IMEEEC), 2016, p. 030027-(1-4).

[24]X. Tang, S. Alavi, and T. J. Herald, "Barrier and mechanical properties of starch-clay nanocomposite films," Cereal Chem., vol. 85, no. 3, pp. 433-439, 2008.

[25]H. R. Dennis, D. L. Hunter, D. Chang, S. Kim, J. L. White, J. W. Cho, and D. R. Paul, "Effect of melt processing conditions on the extent of exfoliation in organoclay-based nanocomposites," Polymer (Guildf)., vol. 42, no. 23, pp. 9513-9522, Nov. 2001.

[26]A. M. Slavutsky, M. A. Bertuzzi, and M. Armada, "Water barrier properties of starch-clay nanocomposite films," Brazilian J. Food Technol., vol. 15, no. 3, pp. 208-218, Sep. 2012. 
[27]H.-M. Wilhelm, M.-R. Sierakowski, G. P. Souza, and F. Wypych, "Starch films reinforced with mineral clay," Carbohydr. Polym., vol. 52, no. 2, pp. 101-110, May 2003.

[28] G. Bhat, R. R. Hegde, M. G. Kamath, and B. Deshpande, "Nanoclay reinforced fibers and nonwovens," J. Eng. Fiber. Fabr., vol. 3, no. 3, pp. 22-34, 2008.

[29]J. W. Ho, L. T. Sin, S. T. Bee, and T. T. Tee, "Mechanical properties investigation on thermoplastic starch (TPS) / montmorillonite nano-clay (MMT)/ alumina trihydrate (ATH) nanocomposites film," in Conference Paper Paper Number 2CE13, 2014, pp. 1-16.

[30]M. A. Omotoso, O. S. Adeyefa, E. A. Animashaun, and O. Osibanjo, "Biodegradable starch film from cassava, corn, potato, and yam," Chem. Mater. Res., vol. 7, no. 12, pp. 15-24, 2015.

[31]M. G. Lomelí-Ramírez, S. G. Kestur, R. Manríquez-González, S. Iwakiri, G. B. de Muniz, and T. S. Flores-Sahagun, "Bio-composites of cassava Starch-green coconut fiber: Part II-Structure and properties," Carbohydr. Polym., vol. 102, no. 1, pp. 576-583, Feb. 2014.

[32]B. Stiller, "The effect of montmorillonite nanoclay on mechanical and barrier properties of mung bean starch films," Thesis Clemson University, 2008.

[33]P. Kampeerapappun, D. Aht-ong, D. Pentrakoon, and K. Srikulkit, "Preparation of cassava starch/montmorillonite composite film," Carbohydr. Polym., vol. 67, no. 2, pp. 155-163, 2007.

[34] M. S. Nazir, M. H. M. Kassim, L. Mohapatra, M. A. Gilani, M. R. Raza, and K. Majeed, "Characteristic Properties of Nanoclays and Characterization of Nanoparticulates and Nanocomposites," in Nanoclay Reinforced Polymer Composites, M. Jawaid, A. el K. Qaiss, and R. Bouhfid, Eds. Singapore: Springer Singapore, 2016, pp. 35-55.

[35]S. Kumar and P. Maiti, "Understanding the controlled biodegradation of polymers using nanoclays," Polymer (Guildf)., vol. 76, pp. 25-33, Oct. 2015.

[36]M. Shayan, H. Azizi, I. Ghasemi, and M. Karrabi, "Effect of modified starch and nanoclay particles on biodegradability and mechanical properties of cross-linked poly lactic acid," Carbohydr. Polym., vol. 124, pp. 237-244, Jun. 2015.

[37]S. Supriyono, H. H. Kusuma, M. Mulyatun, and K. B. Niski, "Synthesis and Characterization of Cassava Shell Based Biodegradable Plastic with Kitosan Addition," J. Nat. Sci. Math. Res., vol. 3, no. 1, pp. 198 202, 2017.

[38]N. A. Ismail, S. Mohd Tahir, N. Yahya, M. F. Abdul Wahid, N. E. Khairuddin, I. Hashim, N. Rosli, and M. A. Abdullah, "Synthesis and Characterization of Biodegradable Starch-Based Bioplastics," Mater. Sci. Forum, vol. 846, no. June 2017, pp. 673-678, Mar. 2016.

[39]D. Prashar and S. Kumar, "Synthesis, Characterization and Evaluation of Physical Properties of Biodegradable Composites from Corn Starch," J. Pharmacogn. Phytochem., vol. 1, no. 2, pp. 20-26, 2012.

[40]H. K. Webb, J. Arnott, R. J. Crawford, and E. P. Ivanova, "Plastic Degradation and Its Environmental Implications with Special Reference to Poly(ethylene terephthalate)," Polymers (Basel)., vol. 5, pp. 1$18,2013$. 